\title{
PUBLIC MODEL OF INTELLECTUAL PROPERTY MANAGEMENT FOR AR4D- SYSTEMS (AGRICULTURAL RESEARCH FOR DEVELOPMENT)
}

\author{
Iryna L. Lytvynchuk*, Kateryna V. Molodetska, Oleh V. Skydan, Lesia V. Zaburanna
}

Polissia National University, Zhytomyr, Ukraine.

ART ICLE INFO

\section{Article History}

Received: April 21, 2021

Revised: July 1, 2021

Accepted: July 30, 2021

\section{Keywords}

Intellectual property

policymaking

Development

Agricultural science

Ukraine
A B S T R A C T

The paper attempts to define the trends of the intellectual property (IP) management in the framework of an agrarian economy. The object of the investigation are the controversies of intellectual property relations in the systems of agricultural research for development (AR4D-systems) that testify to the difficulties in IP management. Taking into account a global trend of changing the correlation of private and public interests to the benefit of the latter in terms of managing intellectual property in AR4D-systems, the paper aims to develop a comprehensive model of intellectual property public management (that guarantees fair balance of interests) and to clarify how to evaluate the integral efficiency of such model. The theoretical basis of the study were existing analytical investigations of the intellectual property policies (conventional policy standard; open innovation policy; mixed policies of combining intellectual property rights regimes). The main obtained result of the study is a general concept of the comprehensive model of intellectual property public management for the AR4D systems based on 5 managing clusters. The integral efficiency monitoring of the proposed model was tested on the example of Ukraine with the help of the methods of multicriteria optimization of the vector criterion. The results show that the integral efficiency of the Ukrainian model is higher than average, but it can be increased by improving the tools of the information and communication support cluster and the cluster of organizational and technical assistance and capacity building such as the availability of the mobilization fund, the availability of the specialized electronic credit and investment platforms, the level of awareness of the users, the number of users of the system's electronic services. The practical value of the obtained results is their strategic impact on a sustainable development policy.

Corresponding Author: Iryna L. Lytvynchuk

Email: ilytvynchuk6375@unesp.co.uk

(C) The Author(s) 2021.

\section{INTRODUCTION}

At the end of the XXth century, after the rapid increasing of aggregate demand for agricultural products, globalization of agricultural markets, internationalization of environmental costs and food safety requirements etc., agricultural production had become the important topic on the agenda of top management of states, transnational corporations, international organizations and integration groups (Ivashchenko et al., 2019). Unprecedented increases in public and private venture capital investment in biotechnology, agricultural robotization and development of innovative food products (in some countries 20-30 times during the 25 years) have created the basis for building a global network of agricultural research for development (AR4D) (Svoboda, 2019). The 
number of transactions with intellectual products has increased dramatically and the procedures for protecting the rights of creators have become more complicated, which has built the basis for the formation of a modern institute of intellectual property management in the framework of the agrarian economy (Granstrand, 1999).

It took time to understand that the intellectual property (IP) relations (IPR) in AR4D systems have a particular specificity, since in such systems the negative consequences of individualizing the contribution of the creator to the technology development outweigh the positive ones because of the food and ecological security. Thus, a defining feature of the IPR specification in the AR4D system is the large proportion of the use of the "polysubjective form of IP" (Lytvynchuk, 2017) due to the strategic importance of sectoral intellectual products such as plant varieties, agricultural technologies, qualified geographical indications of origin for food production (Boettiger et al., 2012). To address this specificity, it is necessarily to provide an effective IP management policy. Taking into account "the global trend of changing the ratio of private and public interests in favor of the latter in matters of IP issues in the agrarian sphere" (Skydan and Lytvynchuk., 2019) as a result of attraction of agricultural knowledge to the "negative intellectual property space" (Tatu et al., 2019) due to their attribution to the world public goods - there is a need for a new managing mechanism to implement a long-term public policy, backed by a social mission and conceptual vision of strategic change in the context of a global development (Jefferson and Camacho., 2014).

All the problems of governmental policies for IP are the evidence of incapability of the management to strike a balance between the social well-being in short-term period and innovative development for future (Baran and Zhumabaeva, 2018). Thus, the purpose of this paper is to develop a comprehensive model of intellectual property public management that guarantees fair balance of interests in the AR4D systems and offer how to evaluate the integral efficiency of such model.

\section{Theoretical overview}

For AR4D system's IP object, to preserve traditional agricultural knowledge of particular communities, the monopoly of the private form and the development of cross-patenting and patent pools must be limited by the factor of involvement of numerous public stakeholders in the processes of IP generation and circulation. The typology of public IP policies in the world at present is represented by: 1) "conventional policy standard" based on the intensification of intellectual property rights protection with the maximum engagement of legal tools to obtain exclusive monopoly property rights; 2) "open innovation policy" oriented towards the liberalization of using target knowledge threads by users in order to accelerate innovation processes; 3 ) "mixed policies of combining intellectual property rights regimes" oriented towards the conflict resolution of the previous two dichotomic models (Lytvynchuk, 2017). All those models have their own implementation threats for the actors of global agrarian research network: geopolitical threat of "intellectual slavery", conflict with free trade principles, high costs of support, problem of balance of exclusive rights and accessibility of knowledge - for the first model; the problem of exploitation of knowledge workers and "free riders", the risk of losing projects with unconfirmed social value, unpaid transaction costs - for open innovation policy; the AR4D system' dysfunction in a case of the indefinite legal framework for the model, the threat of domination of the interests of a certain group of entities - for mixed policies (Brand and Leland., 2016; Chernyakhovskaya and Nizamutdinov., 2019; Duanyang and Wei., 2017; Lytvynchuk, 2017; Rao and Sastry., 2008; Thaher et al., 2019).

Among the global AR4D community, there is a clear trend towards increasing the so-called "polarity of classic IP protection policy and alternative models" (Lytvynchuk, 2017) that encourage user access to agricultural innovation. The classic model, based on the exclusive monopoly ownership rights, is developing in the direction of promoting knowledge trade, by this threatening the loss of sovereignty over biological and genetic resources in developing countries (Edler et al., 2015). Meanwhile, the alternative models stimulate the development of social initiatives through the technological transfer, but increase the risk of potential conflicts of interests, since they make the subjects of intellectual property relationships dependent on the biosafety regimes and land rights (Bercovici et al., 2019; Meissner, 2019). Thus, the knowledge-sharing models (Machinery Link Sharing, USA; SUFE, USA; Farm Backup, Denmark) become an impediment to using intellectual property as a "game card" in trade negotiations and geopolitical conflicts. The appropriation of biological and genetic resources and their transformation into assets 
capable of generating profit (commodification) have been observed, with the consequence of restricting access to germplasm of plants and research instruments. "Patent hacks" resulting from the large fragmentation of rights to agricultural biotechnology, leads to inhibition of biotechnological research and the effect of underutilization of intellectual resources (Payumo et al., 2018; Trommetter, 2006).

It forces the private sector to seek ways to coexist with the public sector on ethical IP issues; issues of biosecurity and food quality; issues of planning and formation of national systems for management of traditional agricultural and environmental knowledge and genetic resources; issues of intellectual products with the status of international and national public goods (Evaluation of Capacity..., 2018). As a result, there is increasing attention in society to free access to selection breeding technologies; to exclusive licenses for patented inventions; to social privileges, exceptions and restrictions on IPR in the public interest (mandatory licensing, exemption for research, etc.); to developing the Giant Patent Donation Institute for Non-profit Organizations. Experts point to AR4D network tightening and growing institutional convergence to bring biotechnology research together due to the high cost of producing biological and genetic resources (creating world banks and collections of mutants, bacterial, etc.). At the same time, the conditions of international cooperation are not always equally beneficial for all participants (due to differences in public and private sector capacities), leading to benefits of strategic use of IPR, especially for developing countries (Litschka and Pellegrini., 2019; Ren et al., 2017).

All mentioned factors lead to a number of the controversies in the development of intellectual property relations in an agrarian economy (which were investigated deeply by (Lytvynchuk, 2017), notably, between "expanding the application of intellectual property rights" and "enhancing the riskogenics of intellectual property relations"; between "commodification of biological and genetic resources" and "development of social initiatives against the monopolistic and oligopolistic expansion" in the field; between "unification of intellectual property legal standards" and "rigidity of a global system"; between "strengthening of control over intellectual property rights infringements" and "advancement of grey practices") (IP in Europe, 2020; IP5 statistic reports, 2020). Those controversies testify to the difficulties in management and the lack of any conceptual model to regulate the institutionalization processes of agrarian intellectual property with respect for specific aspects in this field.

\section{MATERIALS AND METHODS}

The thesis uses a set of general and special methods of scientific knowledge: induction, deduction, analysis and synthesis - to substantiate the theoretical and methodological base of the research; benchmarking methods - for comparing models of public intellectual property management policies; expert polls - to assess the success of IP management tools in the AR4D systems; statistical-economic and mathematical methods - to study the dynamics of the indicators; scientific abstraction - to summarize research findings and formulate conclusions. The logic of the investigation is presented below:

1st step - developing IP management model for the AR4D systems. It was supposed that possible way to increase the social responsibility of the intellectual property entities, to correct the shortcomings of the existing system and to ensure the balance of interests of stakeholders is to develop a mechanism of public administration for intellectual property. Such mechanism was defined and described in detail as a set of measures, decisions, actions, tools, technologies of planning, organization, motivation and control, aiming to provide on the basis of participation the productive interaction for institutions of power and society in the process of intellectual property framework development. Afterwards, using cluster method, the system of institutional managing clusters was represented with the algorithm for its implementation into the general macrosystem of innovation management bodies.

$2^{\text {nd }}$ step - determining the integral efficiency of the proposed mechanism. To evaluate the general indicator (I), there were taken the subindicators for all managing clusters $x_{j}^{k}, k=\overline{1.5}, j=\overline{1.8}$, (Figure 1 ).

To implement the procedure for evaluating the efficiency of the mechanism, the indicators were formalized based on summarized World Intellectual Property Organization (WIPO) data and expert assessments. Some indicators were defined as logical, which acquire values 1 or 0 , while others - as qualitative indicators with 
corresponding numerical values at a given interval. The provided in Table 1.

relevant scales for evaluating the indicators are

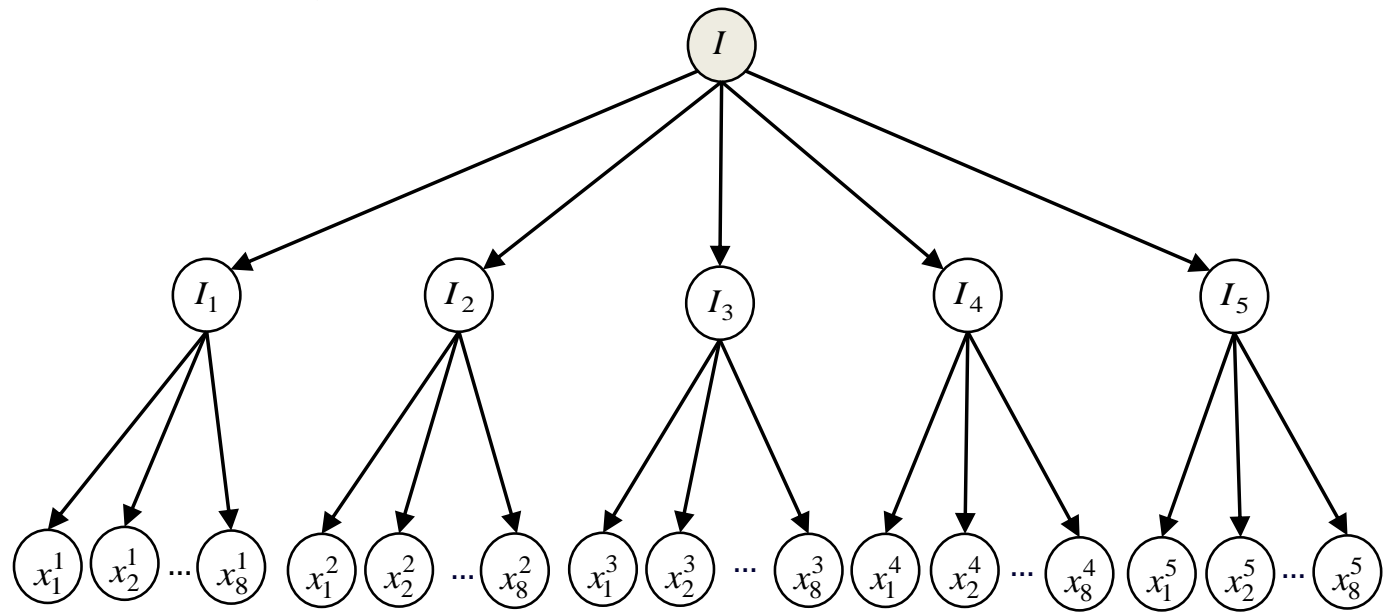

Figure 1. Hierarchical tree (graph) of indicators of the efficiency of the public IP management mechanism in the AR4D systems.

Table 1. A rating scale for institutional cluster's indicators.

\begin{tabular}{|c|c|c|c|}
\hline Indicator designation & Numeric values* & Rating scale & Quality Score \\
\hline \multirow{5}{*}{$x_{1}^{1}$} & - & $0.81-1.00$ & High \\
\hline & - & $0.61-0.80$ & Above average \\
\hline & - & $0.41-0.60$ & Average \\
\hline & - & $0.21-0.40$ & Lower than the average \\
\hline & - & $0.00-0.20$ & Low \\
\hline \multirow{5}{*}{$x_{2}^{1}$} & - & $0.81-1.00$ & High \\
\hline & - & $0.61-0.80$ & Above average \\
\hline & - & $0.41-0.60$ & Average \\
\hline & - & $0.21-0.40$ & Lower than the average \\
\hline & - & $0.00-0.20$ & Low \\
\hline \multirow{5}{*}{$x_{3}^{1}$} & - & $0.81-1.00$ & High \\
\hline & - & $0.61-0.80$ & Above average \\
\hline & - & $0.41-0.60$ & Average \\
\hline & - & $0.21-0.40$ & Lower than the average \\
\hline & - & $0.00-0.20$ & Low \\
\hline \multirow{5}{*}{$x_{4}^{1}$} & above 500000 & $0.81-1.00$ & High \\
\hline & $100000-500000$ & $0.61-0.80$ & Above average \\
\hline & $50000-100000$ & $0.41-0.60$ & Average \\
\hline & $10000-50000$ & $0.21-0.40$ & Lower than the average \\
\hline & $0-10000$ & $0.00-0.20$ & Low \\
\hline \multirow{5}{*}{$x_{5}^{1}$} & above 20 & $0.81-1.00$ & High \\
\hline & $16-20$ & $0.61-0.80$ & Above average \\
\hline & $11-15$ & $0.41-0.60$ & Average \\
\hline & $6-10$ & $0.21-0.40$ & Lower than the average \\
\hline & $0-5$ & $0.00-0.20$ & Low \\
\hline \multirow{2}{*}{$x_{6}^{1}$} & - & 1 & Exist \\
\hline & - & 0 & Does not exist \\
\hline
\end{tabular}




\begin{tabular}{llll}
$x_{7}^{1}$ & - & 1 & Exist \\
& - & 0 & Does not exist \\
$x_{8}^{1}$ & - & $0.81-1.00$ & High \\
& - & $0.61-0.80$ & Above average \\
& - & $0.41-0.60$ & Average \\
& - & $0.21-0.40$ & Lower than the average \\
& - & $0.00-0.20$ & Low \\
\hline
\end{tabular}

Note: * Provided if the indicator is quantified.

The final procedure of estimating the indicator $I$ was a task of multicriteria optimization of the vector criterion. Among the methods used to solve such tasks, to the methods based on compromise (Hryshchuk, 2010) were chosen as far as the alternative ways (methods for optimizing the hierarchical sequence of quality criteria or methods for determining the set of non-improving solutions) have a row of difficulties. The main disadvantages are the complexity of the procedure for determining the structure of the hierarchical sequence of partial indicators and the significant limitations of the non-improvement decisions by the compromises (Molodetska-Hrynchuk, 2017).

The group of methods, which is based on a fair compromise, allows to decrease the quality of some indicators, without not exceeding the quality improvement of the other indicators. In this investigation the non-linear scheme of compromises (Voronyn, 1992; Voronyn and Zyatdynov., 2008) was applied. Such an approach provided a compromise between partial indicators and made the resulted solution optimal according to the Pareto criteria. Additional advantages of the method were, firstly, the computational simplicity; secondly, the unimodality of the scalar convolution, which ensured single-extremality of the task; and finally, adaptation to decision-making conditions. Multicriteria task of estimation of indicators of the first level $\left\{I_{k}^{*}\right\}$ was reduced to a vector optimization model with different weight coefficients for the efficiency indicators of the public IP management mechanism (Eq. 1):

$I_{k}^{*}=\arg \min _{R \in M} \sum_{j=1}^{m} \beta_{j}^{k}\left(1-x_{j}^{k}\right)^{-1}, k=\overline{1,5}, m=8$,

where: $\beta_{j}^{k}$ - the weights coefficients of the indicators $x_{j}^{k}$. The scalar convolution (1) was normalized to the minimum value (Eq. 2):

$I_{k}=1-\frac{1}{I_{k}^{*}}$.

Then, the indicator of the integral efficiency of the public IP management for the AR4D system $I^{*}$ was determined on the basis of previously obtained values $\left\{I_{k}\right\}$ similarly to the expression (1) (Eq. 3):

$I^{*}=\arg \min _{R \in K} \sum_{j=1}^{k} \alpha_{k}\left(1-I_{k}^{*}\right)^{-1}$,

Where:

$\alpha_{k}$ - the weights coefficients of the generalized indicators $I_{k}$. The normalized value of the scalar convolution (3) was similarly determined on the basis of the expression (Eq. 4):

$I=1-\frac{1}{I^{*}}$.

The values of the weights factors $\alpha_{k}$ and $\beta_{j}^{k}$ were set by the experts based on their individual preferences and were corresponded to the actual situation in the AR4D system. Weights coefficients $\alpha_{k}$ were determined on the basis of the simplex (Eq. 5):

$\alpha_{k} \in \Gamma_{\alpha}, \Gamma_{\alpha}=\left\{\alpha_{k} \geq 0, \sum_{k=1}^{l} \alpha_{k}=1\right\}, k \in[1 ; l]$.

The parameters $\alpha_{k}$ also represented the weights coefficients of the regression model of the expert's utility based on the concept of a non-linear scheme of the compromises. Therefore, the weights coefficients were calculated according to the next formula (Eq. 6):

$\alpha_{k}=\frac{f_{k}}{\sum_{i=1}^{l} f_{i}}, k \in[1 ; l]$,

where: $f_{k}$ - the assessment of the priority of the indicator, set by the expert.

In the case when the individual indicators $x_{j}^{k}$ acquired only limit values of 0 or 1 , it characterized the high level of tension of the situation. It occured when the values of the indicators were approached to the limit (Eq. 7):

$\rho_{j}^{k}=1-x_{0 j}^{k}, \rho_{j}^{k} \in[0 ; 1], j \in[1 ; m]$.

In order to eliminate the case of dividing by zero in expression (5) for the values of indicators $x_{j}^{k} \geq 0.95$ there were used the value $x_{j}^{k}=0.95$. The value, obtained according to expression (4), was compared with the qualitative scale of the integral efficiency (Table 2), formed on the basis of the inverted normalized fundamental scale (Voronyn, 2009). The resulting qualitative evaluations were used for policymaking. 
Table 2. The qualitative scale of the integral efficiency.

\begin{tabular}{lc}
$\begin{array}{l}\text { Qualitative Value of the Integral } \\
\text { Efficiency }\end{array}$ & $\begin{array}{c}\text { Interval Values } \\
\text { of the Scale }\end{array}$ \\
\hline High & $0.71-1.00$ \\
Above average & $0.51-0.70$ \\
Lower than the average & $0.31-0.50$ \\
Low & $0.00-0.30$ \\
\hline
\end{tabular}

\section{RESULTS AND DISCUSSION}

Due to the represented vision the mechanism of public administration for intellectual property should include targeting, methodological and instrumental blocks. The elements of the targeting block are general (matching the controversies of the intellectual property policies) and specific objectives (completeness of reforming, focus on stimulating economic issues instead of IP protection, development IP and technical expertise, progress in the field of automation of registration processes, effective communication strategies, decrease of transaction costs etc.). The methodological block includes principles (pragmatism, transparency, subsidiarity, reflection, integration of rational and emotional, objectivity, dynamism, logic, correlation with Significant Changes in Society), regulations and rules (Oslo and Frascati manuals, Lambert Toolkit). The instrumental block covers resources (human, financial, informational), functions (planning, organization motivation, control) and tools (organizational, economic, legal). In addition, the mechanism is characterized by the levels of implementation (operational, tactical, strategic), the character of the relations (internal or external, vertical or horizontal), and the effects (achievement of the goals, adaptation to the external environment, balancing the expectations of stakeholders, optimization of costs).

The mechanism of public administration for AR4D system's intellectual property goes beyond the logic of attributing research products for environmental and food safety to economic public goods. It seeks to contribute to the full and timely disclosure of agricultural research findings as well as to provide the access to the genetic resources and patented agricultural and biotechnologies. According to this set of the goals, the implementation of the mechanism into the general system of innovation management bodies will cover three stages: development, execution and control of efficiency (Figure 2).

In the first phase of national and international consultations (with the involvement of Compound annual growth rate, Public Intellectual Property Resource for Agriculture, European collective management of Public Intellectual Property for Agricultural biotechnologies, European Network of Scientists for Social and Environmental Responsibility, national ministries and other partners) it is expected to form five transmission clusters, responsible for organizational, regulatory, financial, HR, information and other support tools, which are broadly in line with the WIPO Global Development Agenda (Methodology for the Development..., 2016a, b, c):

cluster 1 - organizational and technical assistance and capacity building;

cluster 2 - rulemaking and law;

cluster 3 - information and communication support;

cluster 4 - assessment, impact studies and strategic planning;

cluster 5 - institutional issues.

The main task of the capacity building cluster is to provide IP-management system with financial resources (through the crowdfunding; peer-to-peer lending; financial customization methods; blockchain technologies; mobilization of an IP-management fund in at least $5 \%$ of the agricultural research budget etc.); human resources (through the educational training programs AR4D specialists in the field of the intellectual property) and infrastructural support (through the creation of open advisory platform on intellectual property). The cluster of rulemaking and law in the public mechanism is assigned the role of preparing proposals for the National Intellectual Property Development Strategies (based on the specifics of the agriculture), the main function of which should be used to ensure the proper use of alternative models of the intellectual property rights specification without the direct ignoring of the patentability standards. Meanwhile, the following should be achieved: effective procedures for determining patentable developments; standards of rights' protection, taking into account the need for sufficient disclosure of information in a patent application; determining fair conditions for access to genetic materials and agricultural knowledge; rules for legitimate free use of protected intellectual property for the purposes of agricultural research; determining the transparent order of compulsory licenses' enforcement; regulation of public-private partnership issues in the field of agricultural research; legislative enshrining for the indication the geographical source of the genetic 
resources underlying the invention in the patent applications; mechanisms for legal counteraction to the fragmentation of intellectual property rights in the public sector (Methodology for the Development..., 2016a, b, c).

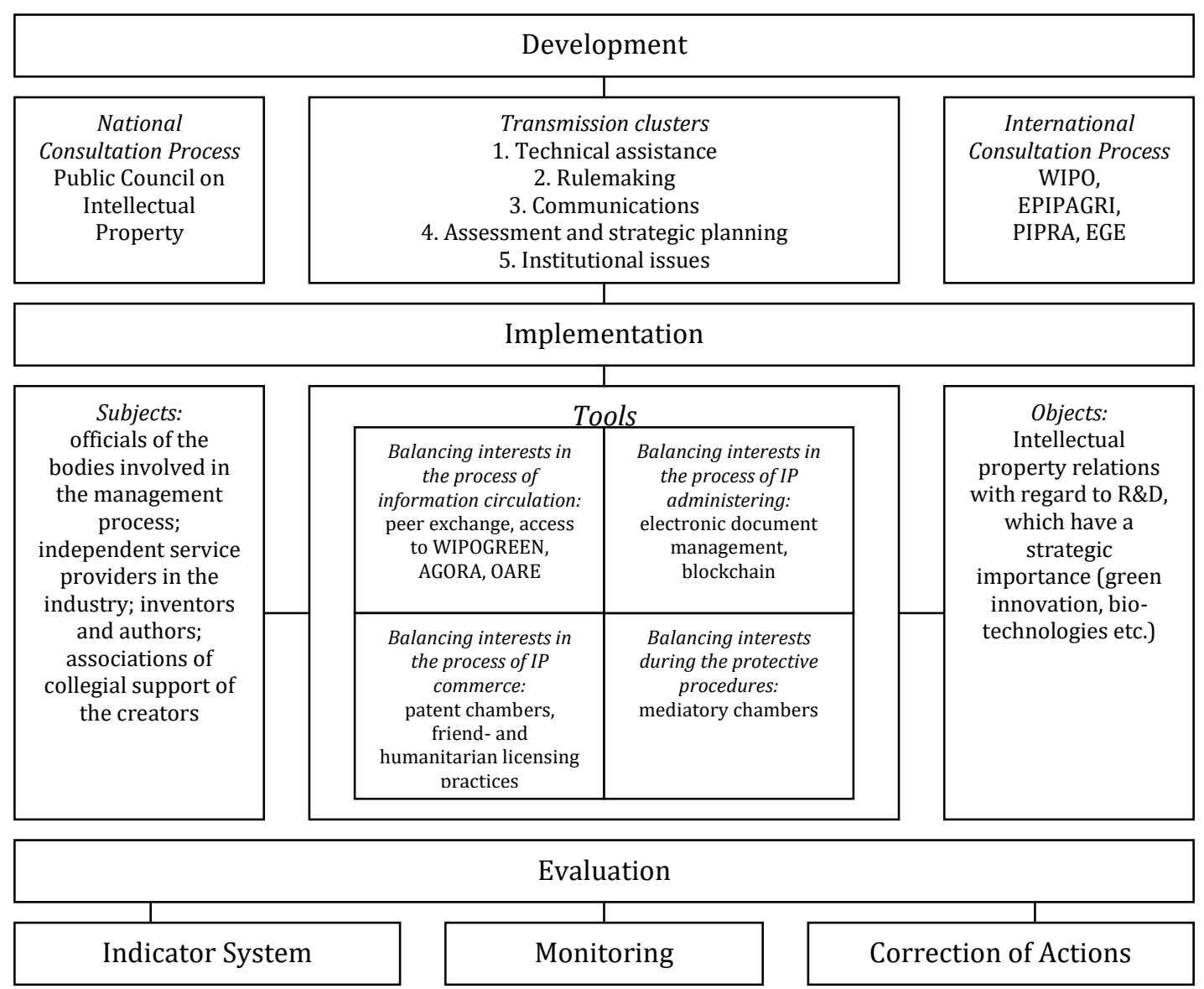

Figure 2. IP public policy mechanism for the system of AR4D.

Those activities should be guided by the recommendations of the United Nations Framework Convention on Climate Change (UNFCCC) (The 45 Adopted..., 2016), which raised the issue of intellectual property on green technologies; by resolution of the Organisation for Economic Co-operation and Development Working Group on Biotechnology (WPB) seminar "Mechanisms for Collaboration in Intellectual Property in the Life Sciences" (Paris, 4-5 May 2009); by methodological tools for cross-border cooperation (CREST).

The Information and communications technology cluster is assigned the role of providing stakeholders with access to global patent and scientific and technical information bases in the field of food and agriculture, health care, environment (such as AGORA and OARE). It also will be responsible for the externalization of economic and business information, generated by the system to improve policy analysis and business decisionmaking.

The task of the cluster of assessment and strategic development is to provide mechanisms of accountability to the public society regarding the economic, social and cultural role of intellectual property in agricultural research. It is important to ensure that stakeholders are informed about the dynamics of intellectual property creation, registration and commercialization; and to provide full information concerning the infringements in the field of intellectual property and the procedures for civil, administrative and/or criminal protection of intellectual property owners.

The institutional cluster will address the issues of improving the architecture of the intellectual property management system and the coordination of relations with intergovernmental and non-governmental international organizations in the AR4D network 
involved in the IP-regulation. For this cluster it is extremely important to ensure the representation of all possible stakeholders involved in the consultation process, including officials of the National IP Offices and institutions; specialists in the field of intellectual property (patent attorneys, lawyers, managers, experts, auditors); authors and inventors from the private and public (universities, research institutions and organizations) sectors; business agents, working in the intellectual property markets; associations of authors; PAE-companies (patent assertion entities whose main activity is to obtain commercial profits from other companies in the market based on patents) etc. It is fully recommended also to provide an active and transparent public discussion of the issues concerned the crosssectoral policies; long-term IP-development programs; the best international benchmarking practices for implementing publicity elements in IPMs.

The second stage of implementation of the mechanism of public IP-management for the AR4D-system contains the development of tools aimed at balancing the interests of stakeholders in the processes of:

a) ensuring circulation of information (peering exchange, open platforms);

b) administration of property relations (typical agreements, electronic document flow);

c) economic circulation of intellectual products (patent pools, clearing houses, practices of humanitarian licensing);

d) application of protective procedures (mediation, cross-repression).

In order to meet expectations of stakeholders during the circulation of information, it is extremely important to stimulate intellectual property entities to participate in the activities of the WIPO GREEN platform which aims to combine owners of new "green" technologies (energysaving, alternative energy sources, ecotransport, ecological forms of agriculture and forestry, etc.) with individuals or companies, who are interested in technological transfer. Today, WIPO GREEN has two components: 1) a database of identified needs and IP assets classified into 9 areas: Agriculture and Forestry, Energy, Water, Pollution and Waste, Chemistry and Modern Materials, Transportation, Building and Construction, Green Products, Other Areas; 2) a network that serves as a global platform for partnerships (The New WIPO..., 2008).
To balance stakeholders' interests in intellectual property management processes, it is advisable to tailor the Lambert Toolkit (LT). LT is a set of full-fledged legal agreements that have been developed in the UK to facilitate negotiations between education, science, business and government representatives to reduce transaction costs associated with the organization of intellectual property interactions under different scenarios. Dealing with such basic issues as liability, state aid, tax breaks, privacy, property rights etc., the developers concluded that previous models (templates, frameworks of contracts) were insufficient as far as they left too many reasons for misunderstanding and negotiations. Experience in the Lambert Code application indicates that a public governance mechanism should provide at least 4 types of agreement: a participation agreement (which confirms the acceptance of intellectual property policy by employees), a service agreement (in which the party agrees to perform certain tasks in accordance with the established specific criteria and requirements); intellectual property transfer agreement and confidentiality agreement. It is proposed also to create a Global of Intellectual Property in the AR4D based on blockchain technology (to deposit information about the IP objects and their holders).

In order to avoid conflicts in the process of IP economic circulation, the mechanism of public administration should overcome the fragmentation of intellectual property rights to agricultural technology. The fragmentation means division of intellectual property rights between private and public ownership, which does not provide full control of the technology and multiplies zones of so-called "non-property". To solve this problem, there were recommended a few ways - an active application of humanitarian and friend-licensing, creation of patent and clearing pools (based on USA experience of patent and clearing houses, Eco-Patent Commons joined by IBM, Nokia, Pitney Bowes, Sony, Bosch, DuPont, Xerox, Fuji Xerox and Dow Chemical). Pools provide the means by which a large group of technology users can obtain the intellectual property rights, required to use specific units of knowledge. For instance, the clearing pools provide ready-made sets of rights to be licensed, while the patent pools let make a choice for user. Appropriate pools can exist both on a commercial (at the expense of registration fees) and non-commercial, philanthropic basis (thanks to opensource technologies). However, it should be taken into 
account that establishing the pools in the field of life sciences is more difficult in comparison with other industries due to the next reasons: firstly, the power and incentives associated with intellectual property rights, as a rule, are less symmetrical there, and secondly, the composition of the subjects involved in intellectual property dealings is more diverse, which makes more difficult to find a compromise and a flexible substitute for standards (Transfer of technology..., 2014).

Balancing the interests of stakeholders in the process of intellectual property legal protection in accordance with the proposed mechanism implies the active promotion of mediator practices. Mediation is a type of alternative dispute resolution involving an uninterested, neutral mediator, who helps the parties of the conflict to establish a communication process and to analyze the situation so that they themselves can choose the common satisfied solution. Unlike an arbitration hearing or litigation, the mediator does not make a decision during mediation, but helps the parties to find it independently, based more on their interests, not on legal positions and contractual rights. Thus, the regulated use of mentioned tools, on the one hand, will ensure fair access to public goods in the AR4D system, and on the other hand, will solve a number of problems that cause IP owners to be extremely cautious about forms of joint ownership. Among these problems, experts highlight possible escalation of costs due to the legal and cultural differences of co-owners; potential complexity of intellectual property protection due to the lack of clear decisions as to which party is responsible for the registered intellectual property; complications during business negotiations about commercialization, especially in the context of attracting international partners.

Finally, the third stage of the implementation of the IP public policy for the AR4D system is the assessment and control, which provides the monitoring of the management system in order to identify possible deviations from the planned indicators and execute corrective procedures. However, the difficulty of carrying out this stage is the lack of a generally accepted methodology of evaluation due to the specifics of qualitative and quantitative comparisons of the intangible component of the agrarian economy. Determining the integral efficiency of a mechanism for public governance based on the evolution of indicators, it should be taken into account that quantitative assessment is extremely difficult given the diversity of socio-economic outcomes that can't be thrown to a single measure. Firstly because of the reform outcomes will show returns only in the long term (the delay factor), secondly, there is the complexity of attributing the result to a specific tool for the comparison of costs and benefits (due to the synergy of management impacts). Below the obtained results of the integrated system's efficiency are described. To calculate the general indicator, the following indicators of each cluster were taken.

1. For the cluster of institutional issues and responsibilities $\left(I_{1}\right)$ :

- the level of autonomy of the governing bodies in the overall institutional architecture of the state $\left(x_{1}^{1}\right)$;

- the level of automation and modernization of management structures $\left(x_{2}^{1}\right)$;

- the level of ensuring multidisciplinary representation of all possible stakeholders in the management system $\left(x_{3}^{1}\right)$;

- the number of non-governmental organizations involved in the system managing $\left(x_{4}^{1}\right)$;

- the number of partnerships, pools and collaborative programs to promote the effective use of the IP in the system per year $\left(x_{5}^{1}\right)$;

- the availability of an intellectual property court $\left(x_{6}^{1}\right)$;

- the availability of mediator chambers $\left(x_{7}^{1}\right)$;

- the level of the international institutions' satisfaction with coordination activities inside the system $\left(x_{8}^{1}\right)$.

2. For the cluster of rulemaking and regulation $\left(I_{2}\right)$ :

- the number of regulatory documents generated in the system (laws, directives, standards, etc.) $\left(x_{1}^{2}\right)$;

- the level of compliance of the regulations with international agreements, treaties and protocols $\left(x_{2}^{2}\right)$;

- the number of international instruments ratified by the system $\left(x_{3}^{2}\right)$;

- the availability of regulators of fair access to agricultural knowledge and genetic materials $\left(x_{4}^{2}\right)$;

- the availability of the mechanism to counteract the fragmentation of patent rights $\left(x_{5}^{2}\right)$;

- the availability of the civil and administrative procedures of IP protection in the AR4D system $\left(x_{6}^{2}\right)$;

- the availability of the criminal procedures and sanctions for IPR infringement $\left(x_{7}^{2}\right)$;

- the availability of disclosure and accountability mechanisms in the field of IP law and rulemaking $\left(x_{8}^{2}\right)$. 
3. For the cluster of organizational and technical assistance and capacity building $\left(I_{3}\right)$ :

- the number of human resources involved in the management system $\left(x_{1}^{3}\right)$;

- the number of training programs for the specialists in the field $\left(x_{2}^{3}\right)$;

- the level of financial support for management from the state budget $\left(x_{3}^{3}\right)$;

- the number of IP grants $\left(x_{4}^{3}\right)$;

- the availability of the mobilization fund $\left(x_{5}^{3}\right)$;

- the availability of the specialized electronic credit and investment platforms (crowdfunding etc.) $\left(x_{6}^{3}\right)$;

- the availability of the electronic services, mobile and web applications (administrative and financial) for applicants $\left(x_{7}^{3}\right)$;

- the level of technology transfer infrastructure development $\left(x_{8}^{3}\right)$.

4. For the cluster of assessment, impact studies and strategic planning $\left(I_{4}\right)$

- the availability of a research agenda and a mechanism for coordinating research in the context of ongoing life science and technology initiatives $\left(x_{1}^{4}\right)$;

- the number of established new and upgraded existing AR4D laboratories, think tanks $\left(x_{2}^{4}\right)$;

- the number of implemented open joint scientific and research projects $\left(x_{3}^{4}\right)$;

- the availability of data monitoring and evaluation techniques $\left(x_{4}^{4}\right)$;
- the level of intensifying the use of technologies that allow automatic tracking of information in real time $\left(x_{5}^{4}\right)$;

- the level of stakeholders' satisfaction with the IP management in the AR4D system $\left(x_{6}^{4}\right)$;

- the availability of the developed public intellectual property policy $\left(x_{7}^{4}\right)$;

- the availability of a strategy for the IP management development in the AR4D system $\left(x_{8}^{4}\right)$.

5. For the information and communication support cluster $\left(I_{5}\right)$ :

- the level of externalization of information, generated by the system $\left(x_{1}^{5}\right)$;

- the level of informatization of workflow $\left(x_{2}^{5}\right)$;

- the number of open electronic registers in the system $\left(x_{3}^{5}\right)$;

- the number of educational, expert and communication platforms accessed or created $\left(x_{4}^{5}\right)$;

- the number of information campaigns to support IP policy $\left(x_{5}^{5}\right)$;

- the availability of IP communication strategy $\left(x_{6}^{5}\right)$;

- the level of awareness of the users $\left(x_{7}^{5}\right)$;

- the number of users of the system's electronic services $\left(x_{8}^{5}\right)$.

The methodology was applied on the example of Ukrainian AR4D system (Statistical country profiles, 2019). It was established that for our case study the partial indicators $x_{j}^{k}$ acquire the values that are represented in Table 3.

Table 3. Research results for the weight coefficients $x_{j}^{k}$.

\begin{tabular}{|c|c|c|c|c|c|c|c|c|c|c|c|c|c|c|c|c|}
\hline Indicator & $x_{1}^{1}$ & $x_{2}^{1}$ & $x_{3}^{1}$ & $x_{4}^{1}$ & $x_{5}^{1}$ & $x_{6}^{1}$ & $x_{7}^{1}$ & $x_{8}^{1}$ & $x_{1}^{2}$ & $x_{2}^{2}$ & $x_{3}^{2}$ & $x_{4}^{2}$ & $x_{5}^{2}$ & $x_{6}^{2}$ & $x_{7}^{2}$ & $x_{8}^{2}$ \\
\hline Value & 0.4 & 0.5 & 0.2 & 0.1 & 0.2 & 1 & 1 & 0.4 & 0.2 & 0.8 & 0.8 & 0 & 0 & 1 & 1 & 1 \\
\hline Indicator & $x_{1}^{3}$ & $x_{2}^{3}$ & $x_{3}^{3}$ & $x_{4}^{3}$ & $x_{5}^{3}$ & $x_{6}^{3}$ & $x_{7}^{3}$ & $x_{8}^{3}$ & $x_{1}^{4}$ & $x_{2}^{4}$ & $x_{3}^{4}$ & $x_{4}^{4}$ & $x_{5}^{4}$ & $x_{6}^{4}$ & $x_{7}^{4}$ & $x_{8}^{4}$ \\
\hline Value & 0.3 & 0.1 & 0.4 & 0.1 & 0 & 0 & 1 & 0.4 & 1 & 0.1 & 0.2 & 0 & 0.2 & 0.1 & 0 & 0 \\
\hline Indicator & $x_{1}^{5}$ & $x_{2}^{5}$ & $x_{3}^{5}$ & $x_{4}^{5}$ & $x_{5}^{5}$ & $x_{6}^{5}$ & $x_{7}^{4}$ & $x_{8}^{4}$ & & & & & & & & \\
\hline Value & 0.5 & 0.5 & 0.1 & 0.3 & 0.1 & 0 & 0.4 & 0.4 & & & & & & & & \\
\hline
\end{tabular}

To establish the values of the weight coefficients $\alpha_{k}$ and $\beta_{j}^{k}$ there were conducted an expert survey of the staff of the analytical department of IP consulting company. According to the results of the processing of the questionnaire data, the weight coefficients of generalized indicators of the efficiency for public IP management model of UA AR4D system are given in Table 4. The weight coefficients of the partial indicators of the model efficiency were determined in similar way. The results are presented in Table 5.

Table 4. Results of the expert survey for the generalized indicators $\alpha_{k}$.

\begin{tabular}{rcc}
\hline Weight coefficient & Expert Evaluation, Score & Weight coefficient Value \\
\hline$\alpha_{1}$ & 9 & 0.26 \\
$\alpha_{2}$ & 8 & 0.23
\end{tabular}




\begin{tabular}{cccc} 
& $\alpha_{3}$ & 6 & 0.17 \\
& $\alpha_{4}$ & 7 & 0.20 \\
& $\alpha_{5}$ & 5 & 0.14 \\
\hline Total & 35 & \\
\hline
\end{tabular}

Table 5. Results of the expert survey for the partial indicators $\beta_{j}^{k}$.

\begin{tabular}{lcccccccc}
\hline Weight coefficient & $\beta_{1}^{1}$ & $\beta_{2}^{1}$ & $\beta_{3}^{1}$ & $\beta_{4}^{1}$ & $\beta_{5}^{1}$ & $\beta_{6}^{1}$ & $\beta_{7}^{1}$ & $\beta_{8}^{1}$ \\
\hline Value & 0.09 & 0.07 & 0.2 & 0.11 & 0.14 & 0.18 & 0.16 & 0.05 \\
Weight coefficient & $\beta_{1}^{2}$ & $\beta_{2}^{2}$ & $\beta_{3}^{2}$ & $\beta_{4}^{2}$ & $\beta_{5}^{2}$ & $\beta_{6}^{2}$ & $\beta_{7}^{2}$ & $\beta_{8}^{2}$ \\
Value & 0.05 & 0.09 & 0.07 & 0.2 & 0.18 & 0.16 & 0.14 & 0.11 \\
Weight coefficient & $\beta_{1}^{3}$ & $\beta_{2}^{3}$ & $\beta_{3}^{3}$ & $\beta_{4}^{3}$ & $\beta_{5}^{3}$ & $\beta_{6}^{3}$ & $\beta_{7}^{3}$ & $\beta_{8}^{3}$ \\
Value & 0.2 & 0.18 & 0.14 & 0.05 & 0.11 & 0.09 & 0.07 & 0.16 \\
Weight coefficient & $\beta_{1}^{4}$ & $\beta_{2}^{4}$ & $\beta_{3}^{4}$ & $\beta_{4}^{4}$ & $\beta_{5}^{4}$ & $\beta_{6}^{4}$ & $\beta_{7}^{4}$ & $\beta_{8}^{4}$ \\
Value & 0.14 & 0.09 & 0.11 & 0.07 & 0.05 & 0.18 & 0.16 & 0.20 \\
Weight coefficient & $\beta_{1}^{5}$ & $\beta_{2}^{5}$ & $\beta_{3}^{5}$ & $\beta_{4}^{5}$ & $\beta_{5}^{5}$ & $\beta_{6}^{5}$ & $\beta_{7}^{4}$ & $\beta_{8}^{4}$ \\
Value & 0.16 & 0.05 & 0.14 & 0.07 & 0.09 & 0.18 & 0.2 & 0.11 \\
\hline
\end{tabular}

The scalar convolution for the institutional cluster's indicators $\left(I_{1}\right)$ in accordance with expression (1) takes the next form:

$I_{1}^{*}=\frac{0.09}{1-0.4}+\frac{0.07}{1-0.5}+\frac{0.2}{1-0.2}+\frac{0.11}{1-0.1}+\frac{0.14}{0.2}+\frac{0.18}{1-0.95}+\frac{0.16}{1-0.95}+$ $\frac{0.05}{1-0.4}=7.73$.

The scalar convolution value for other clusters were defined similarly:

$I_{2}^{*}=9.42 ; I_{3}^{*}=2.61 ; I_{4}^{*}=3.66 ; I_{5}^{*}=1.47$.

The corresponding normalized values of the partial indicators for each of the clusters were obtained from the expression (2):

$I_{1}=0.87 ; I_{2}=0.89 ; I_{3}=0.62 ; I_{4}=0.73 ; I_{5}=0.32$.

Finally, we determine the value of the integral indicator $I=0.82$. Therefore, the value of the generalized indicator $I$ illustrates the overall success of the introduced managing clusters. It is possible to increase this indicator by improving the tools the information and communication support cluster $I_{5}=0.32$ and the cluster of organizational and technical assistance and capacity building $I_{3}=0.62$. It should be noted that the obtained results are consistent with the Ukrainian statistic data. It totally demonstrates the effectiveness of the proposed evaluation technique.

\section{CONCLUSIONS}

Our findings testified to the growing significance of the problem of balancing the interests of the state, research, education, and agrarian business in the matters of the distribution of intellectual property rights. The IP relations in the AR4D system have specific contradictions, which arise, firstly, between the commodification of IP and social antimonopoly initiatives; secondly, between the multiplication of innovations and the underutilization of intellectual resources as a result of blocking the access to them by the right holders (anti-acquisition effect); thirdly, between diversifying the range of IP management instruments and their competition, and fourthly, between unifying the global standards of IP governance and differentiating national policies on IP protection. The possible way for solving the task of offsetting the effects of the IP relations' contradictions and creating a favorable environment for realizing the interests of AR4D stakeholders is a mechanism of the public IP management, which can restrain monopolistic and oligopolistic tendencies and by this contribute to the levelling of the sectoral counterbalances, stemming from the criteria of social benefit and compromise between the IP holders and other stakeholders.

The integral efficiency of a mechanism for public IP management, can be measured based on a set of indicators of the efficiency of IP institutions (autonomy of the governing bodies in the overall institutional architecture of the state; level of automation and modernization of management structures; level of ensuring multidisciplinary representation of all possible stakeholders in the management system; number of NGOs involved in the system managing; number of 
partnerships, pools and collaborative programs to promote the effective use of the IP in the system per year; availability of an intellectual property court and mediator chambers; level of the international institutions' satisfaction with coordination activities inside the system), IP rulemaking policy and law (number of regulatory documents generated in the system; level of compliance of the regulations with international agreements, treaties and protocols; number of international instruments ratified by the system; availability of regulators of fair access to agricultural knowledge and genetic materials; availability of the mechanism to counteract the fragmentation of patent rights; availablity of the civil, administrative and criminal procedures of IP protection in the AR4D system; availability of disclosure and accountability mechanisms in the field), IP organizational assistance and capacity building (number of human resources involved in the management system; number of training programs for the specialists in the field; level of financial support for management from the state budget; number of IP grants; availability of the mobilization fund, investment platforms, electronic services, mobile and web applications for applicants; level of technology transfer infrastructure development), IP information and communication support (level of externalization of information, generated by the system; level of informatization of workflow; number of open electronic registers in the system; number of educational, expert and communication platforms accessed or created; number of information campaigns to support IP policy; availability of IP communication strategy; level of awareness of the users; number of users of the system's electronic services), IP assessment and strategic planning (availability of a research agenda in the context of ongoing life science and technology initiatives; number of established new and upgraded existing AR4D laboratories, think tanks; number of implemented open joint scientific and research projects; availability of data monitoring and evaluation techniques; level of intensifying the use of technologies that allow automatic tracking of information in real time; level of stakeholders' satisfaction with the IP management; availability of the developed public intellectual property policy; availability of a strategy for the IP management development in the AR4D system).

\section{REFERENCES}

Baran, A. and A. Zhumabaeva. 2018. Intellectual property management in startups - problematic issues. Engineering Management in Production and Services, 10: 66-74.

Bercovici, A., E. G. Bercovici and M. Maftei. 2019. Applying a risk management model in intellectual property management. Quality - Access to Success, 20: 56-60.

Boettiger, S., R. Potter and S. P. Kowalskiю. 2012. Managing intellectual property to foster agricultural development. Agricultural innovation systems: An investment sourcebook. University of New Hampshire, Durham.

Brand, B. and L. Leland. 2016. Intellectual property and agricultural science and innovation in Germany and the United States. Science, Technology \& Human Values, 12: 1-35.

Chernyakhovskaya, L. and M. Nizamutdinov. 2019. Development of knowledge base for intellectual decision support in the process of innovative project management. Paper presented at the proceedings of the 10th international conference on electronics, computers and artificial intelligence. Institute of Electrical and Electronics Engineers Inc., Piscataway.

Duanyang, R. and S. Wei. 2017. The study of agricultural intellectual property and intelligent agriculture development strategies in China. Journal of Service Science and Management, 10: 230-250.

Edler, J., H. Cameron and M. Hajhashem. 2015. The intersection of intellectual property rights and innovation policy making - a literature review. Manchester Institute of Innovation Research, Manchester.

Granstrand, O. 1999. The economics and management of intellectual property: Towards intellectual capitalism. Edward Elgar Publishing Ltd, Cheltenham.

Hryshchuk, R. 2010. Theoretical bases of modeling the processes of attack on information by the methods of theories of differential games and differential transformations. Ruta, Zhytomyr.

Ivashchenko, T. N., N. V. Mironenko, N. E. Popovicheva and T. A. Zhuravleva. 2019. Macro-economic models of implementation of public-private partnership. Experience, Problems and Perspectives, 726: 609-619. 
Jefferson, D. and A. Camacho. 2014. Towards a balanced regime of intellectual property rights for agricultural innovations. Journal of Intellectual Property Rights, 19: 395-403.

Litschka, M. and T. Pellegrini. 2019. Considerations on the governance of open data - an institutional economic perspective. International Journal of Intellectual Property Management, 9: 247.

Lytvynchuk, I. 2017. Intellectual property management in the AR4D systems (agricultural research for development). ZNAEU, Zhytomyr.

Meissner, D. 2019. Public-private partnership models for science, technology, and innovation cooperation. Journal of the Knowledge Economy, 10: 13411361.

Molodetska-Hrynchuk, K. 2017. Method for evaluation of the state information security threaths in social internet-services. Automation of Technological and Business Processes, 9.

Payumo, J. G., S. Assem, N. Bhooshan, H. Galhena, R. Mbabazi and K. Maredia. 2018. Managing agricultural research for prosperity and food security in 2050: Comparison of performance, innovation models and prospects. Open Agriculture Journal, 12: 20-35.

Rao, N. and R. Sastry. 2008. Towards a policy for management of intellectual property in public agricultural research systems in India. Journal of Intellectual Property Rights, 9: 242-259.

Ren, D., W. Song and Z. Ge. 2017. The study of agricultural intellectual property and intelligent agriculture development strategies in China. Journal of Service Science and Management, 10: 230-250.
Skydan, O. and I. Lytvynchuk. 2019. Intellectual property policy for an agrarian economy as a key problem of sustainable development global agenda. In: T. Zinchuk, Y. Ramanauskas (Ed.), Sustainable development of rural areas. Center for Educational Literature, Kyiv.

Svoboda, D. 2019. The innovative state and the intellectual property management of publicly developed environmentally sound technology in the EU. International Journal of Environmental Technology and Management, 22: 415-431.

Tatu, M. A., A. B. Pop and S. Tatu. 2019. The correlation between intellectual property management and quality management in the modern knowledgebased economy. Paper presented at the proceedings of the 10th international conference on electronics, computers and artificial intelligence. Institute of Electrical and Electronics Engineers Inc., Piscataway. Article number 146804.

Thaher, N., H. H. Odame and V. Henson-Apollonio. 2019. Capacity development for intellectual property management in canadian crop biotechnology., 9(34): 287-314. International Journal of Intellectual Property Management, 9: 287-314.

Trommetter, M. 2006. The bioeconomy to 2030: Designing a policy agenda. http://www.oecd.org/sti/biotech/34823102.pdf.

Voronyn, A. 1992. Multicriteria synthesis of dynamical systems. Naukova dumka, Kyiv.

Voronyn, A. and Y. Zyatdynov. 2008. Nonlinear scheme of trade-offs in multicriteria problems. Naukova dumka, Kyiv.

Publisher's note: EScience Press remains neutral with regard to jurisdictional claims in published maps and institutional affiliations.

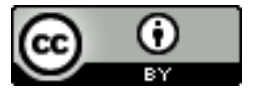

Open Access This article is licensed under a Creative Commons Attribution 4.0 International License, which permits use, sharing, adaptation, distribution and reproduction in any medium or format, as long as you give appropriate credit to the original author(s) and the source, provide a link to the Creative Commons license and indicate if changes were made. The images or other third-party material in this article are included in the article's Creative Commons license, unless indicated otherwise in a credit line to the material. If material is not included in the article's Creative Commons license and your intended use is not permitted by statutory regulation or exceeds the permitted use, you will need to obtain permission directly from the copyright holder. To view a copy of this license, visit http://creativecommons.org/licenses/by/4.0/. 